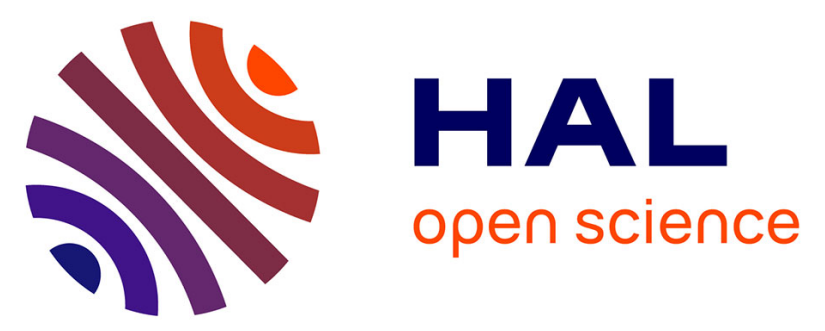

\title{
Combined silencing expression of MGMT with EGFR or galectin-1 enhances the sensitivity of glioblastoma to temozolomide
}

Khaled Messaoudi, Anne Clavreul, Fabienne Danhier, Patrick Saulnier, Jean-Pierre Benoît, Frédéric Lagarce

\section{To cite this version:}

Khaled Messaoudi, Anne Clavreul, Fabienne Danhier, Patrick Saulnier, Jean-Pierre Benoît, et al.. Combined silencing expression of MGMT with EGFR or galectin-1 enhances the sensitivity of glioblastoma to temozolomide. European Journal of Nanomedicine, 2015, 7 (2), pp.97-107. 10.1515/ejnm2014-0041 . hal-01153701

\section{HAL Id: hal-01153701 \\ https://hal.science/hal-01153701}

Submitted on 20 May 2015

HAL is a multi-disciplinary open access archive for the deposit and dissemination of scientific research documents, whether they are published or not. The documents may come from teaching and research institutions in France or abroad, or from public or private research centers.
L'archive ouverte pluridisciplinaire HAL, est destinée au dépôt et à la diffusion de documents scientifiques de niveau recherche, publiés ou non, émanant des établissements d'enseignement et de recherche français ou étrangers, des laboratoires publics ou privés. 
Khaled Messaoudi, Anne Clavreul, Fabienne Danhier, Patrick Saulnier, Jean-Pierre Benoit and Frederic Lagarce*

\section{Combined silencing expression of MGMT with EGFR or galectin-1 enhances the sensitivity of glioblastoma to temozolomide}

\begin{abstract}
For several years, the first line of treatment of glioblastoma (GB) patients is based on surgical resection followed by fractioned radiotherapy with concomitant and adjuvant chemotherapy with temozolomide (TMZ). The effectiveness of this treatment is very limited due to the development by tumor cells of mechanisms of resistance to TMZ such as over-expression of 06-methylguanine DNA methyltransferase (MGMT), epidermal growth factor receptor (EGFR) and galectin-1. In this study, we hypothesized that the targeting of MGMT, EGFR and galectin-1 (alone or in combination) by specifics siRNAs carried by chitosan-lipid nanocapsules (chitosan-LNCs) could enhance the sensitivity of U87MG cells to TMZ. We showed in vitro that (i) anti-MGMT and (ii) anti-EGFR or anti-galectin-1 siRNAs decreased significantly the expression of their corresponding proteins and increased the sensitivity of U87MG cells to TMZ. Additionally, the sensitivity of U87MG/MGMT- cells to TMZ was significantly increased when anti-EGFR and anti-galectin-1 siRNAs were combined with a percentage of living cells of $17.8 \pm 1.6 \%$ at $0.5 \mathrm{mg} / \mathrm{mL}$ concentration of TMZ. The combination of anti-MGMT siRNAs with either anti-EGFR or anti-galectin-1 siRNAs enhanced the sensitivity of U87MG/ MGMT+ cells to TMZ in comparison to their separately use. No difference was observed between the association of the three siRNAs and other associations. At $0.5 \mathrm{mg} /$ $\mathrm{mL}$ concentration of TMZ, the percentage of living cells
\end{abstract}

\footnotetext{
*Corresponding author: Frederic Lagarce, LUNAM Université, Angers, France; Inserm U1066, Micro et Nanomédecines Biomimétiques, IBS, Angers Cedex 9, France; and Service Pharmacie, CHU Angers, France, Phone: +33 244688568 , Fax: +33 244 688546, E-mail: frederic.lagarce@univ-angers.fr Khaled Messaoudi, Anne Clavreul and Patrick Saulnier: LUNAM Université, Angers, France; Inserm U1066, Micro et Nanomédecines Biomimétiques, IBS, Angers Cedex 9, France

Fabienne Danhier: Louvain Drug Research Institute, Université catholique de Louvain, Advanced Drug Delivery and Biomaterials, Avenue Mounier 73 bte B1 73.12, B-1200 Brussels, Belgium Jean-Pierre Benoit: LUNAM Université, Angers, France; Inserm U1066, Micro et Nanomédecines Biomimétiques, IBS, Angers Cedex 9, France; and Service Pharmacie, CHU Angers, France
}

decreased from $55.1 \pm 1.9 \%$ to $36.0 \pm 4.1 \%$ for anti-MGMT alone and the combination of anti-MGMT/anti-galectin-1/ anti-EGFR siRNAs, respectively. These siRNA nanovectors represent a good alternative to enhance the effectiveness of the standard treatment of GB. This method could be implemented in future preclinical models for experimental cancer treatment of GB.

Keywords: EGFR; galectin-1; glioblastoma; MGMT; SiRNA; temozolomide.

DOI 10.1515/ejnm-2014-0041

Received November 5, 2014; accepted March 6, 2015; previously published online March 26, 2015

\section{Introduction}

Glioblastoma (GB) is the most aggressive among brain tumors and the most resistant to current treatment combining surgery, radiation, and chemotherapy by oral Temozolomide (TMZ) $(1,2)$. Median survival is 14 months and the percentage of patients living for 5 years or more is $<10 \%(1,3)$. TMZ is an alkylating agent from the imidazotetrazine family; it acts by methylation of purine bases of DNA (O6-guanine; N7-guanine and N3-adenine) (4). The cytotoxicity of TMZ is mainly mediated by the formation of 0-6 methyl guanine responsible of mispairment with thymine during DNA replication; this causes toxic lesions of DNA and cell cycle arrest $(5,6)$.

The efficacy of TMZ for treating GB is very limited due to TMZ resistance. This is mainly due to high levels of enzyme activity of DNA repair 06-methylguanine DNA methyltransferase (MGMT) expressed in glioma cells (7). This enzyme acts by removing the methyl group from guanine and restores the DNA strand (8). On the other hand, overexpression of epidermal growth factor receptor (EGFR) and galectin-1 by tumor cells significantly contributes to TMZ resistance $(3,9)$. EGFR gene amplification is the most frequent genetic alteration in primary GBs with 
a frequency of $40 \%$ (10), and approximately, half of these tumors carry the rearranged $E G F R$ gene resulting in tumors expressing both wild-type EGFR as well as a mutated EGFR (11). EGFRvIII is the most common variant of EGFR in GB in which the extracellular domain of the receptor is lacking, resulting in constitutive activation (12). EGFR activates strongly Ras/Raf/MAPK (13) and PI3K/AKT/mTOR (14) signaling pathways that cause an inhibition of cell autophagy and apoptosis responsible of the decrease of TMZ efficiency (15). Galectin-1 belongs to lectin family containing a carbohydrate recognition domain (CRD) that confers to galectin- 1 a high affinity for $\beta$-galactosides (3, 16). It acts by stimulation of Ras/Raf/MAPK signaling pathway and by the inhibition of p53 transport to the nucleus that also contributes to TMZ resistance (17).

Given the involvement of MGMT, EGFR and galectin-1 in the pathogenesis of GB, it seems very likely that reducing their cell expression and functionality will improve the sensitivity of GB to TMZ. Various strategies can be used to achieve this goal. Among them, small interfering RNAs (siRNAs) are very promising. They are small doublestranded RNAs of 21-23 bp that reduce the expression of specific genes with complementary nucleotide sequences $(18,19)$. They operate by specific incorporation into RNA induced silencing complex (RISC) that becomes active. Following that, the antisense strand remains in the RISC complex and guides the RNA interference enzymatic machinery while the sense strand of the RISC complex is eliminated. Degradation of the complementary mRNA is provided by nuclease argonaute $2(20,21)$ and leads to a reduced protein expression.

Unfortunately, the use of therapeutic siRNAs alone (i.e., directly injected as naked molecule without any adjuvant) is not possible for several reasons. Among these, (i) their negative charge that prevents them from crossing the plasma membrane to reach their target into the cytoplasm $(20,22)$, (ii) their degradation after their injection into the blood by nucleases present in plasma and cytoplasm (23), and (iii) the immune response that can be triggered by their presence in the blood (23). For these reasons the use of vectors that allow efficient siRNA delivery into the target cells is necessary.

Many non-viral vectors of siRNAs have been developed. They differ from each other by their composition and method of preparation $(24,25)$. Some of these vectors have been designed either to encapsulate siRNAs (26) or to attach them to their surface.

We chose to complex siRNAs to the surface of lipid nanocapsules (LNCs) because of their water-soluble nature and to allow them to be efficient without a need of release from the nanocapsule structure. Additionally, the oily core of these nanoparticles should allow us to consider the co-encapsulation of lipophilic anticancer drugs in the future. In this context, chitosan-transacylated lipid nanocapsules (chitosan-LNCs) have been previously developed for the transport of siRNAs (27). This cationic vector was obtained after grafting chitosan at the surface of LNCs produced by a phase inversion method (28). This process is green: no organic solvents are used. Moreover, only generally recognized as safe (GRAS) and genetically modified organisms (GMO) free excipients are used (29). The positive charge of chitosan allows for fixing the negatively charged siRNAs to the vector surface by electrostatic attraction. Chitosan was selected as the transacylation polymer for its interesting physicochemical properties in particular its non-toxicity and biocompatibility (30).

In a previous study, we highlighted the interest to use anti-EGFR siRNA-chitosan LNCs to increase the sensitivity of GB cells to TMZ (27). Knowing that EGFR overexpression is not the only factor involved in the resistance of GB cells to TMZ, the aim of this work was (i) to produce and characterize siRNA-chitosan LNCs able to target several proteins that participate in TMZ resistance, in particular MGMT, EGFR and galectin-1, and (ii) to study the sensitivity of human GB cells to TMZ after siRNA treatment alone or in combination.

\section{Materials and methods}

\section{Materials}

Solutol ${ }^{\circledR}$ HS 15 (BASF, Ludwigshafen, Germany) is a mixture of free polyethylene glycol 660 (PEG) and polyethylene glycol 660 hydroxystearate, Labrafac ${ }^{\circledR}$ WL 1349 (Gattefossé S.A., Saint-Priest, France) is a mixture of capric and caprylic acid triglycerides, $\mathrm{NaCl}$ was purchased from Prolabo (Fontenay-sous-Bois, France), Lipoïd ${ }^{\circledR}$ S75-3 (Lipoïd $\mathrm{GmbH}$, Ludwigshafen, Germany) is a soybean lecithin made of $69 \%$ of phosphatidylcholine, $10 \%$ phosphatidylethanolamine and other phospholipids, Milli-Q water was obtained from a Milli-Q-plus ${ }^{\circledR}$ system (Millipore, Paris, France). Chitosan oligosaccharide lactate $5 \mathrm{kDa}$ with a degree of deacetylation $\geq 75 \%$ was purchased from Sigma Aldrich (Saint-Quentin Fallavier, France). The dialysis membrane was purchased from Spectrum Laboratories (Rancho Dominguez, USA) and has a molecular weight cut-off point equal to $50 \mathrm{kDa}$. $O$-Phthalaldehyde (OPA) was purchased from Thermo Scientific (Rockford, USA). The 3-(4,5-dimethylthiazol-2-yl)-2,5-diphenyltetrazolium bromide (MTT) was purchased from Sigma Aldrich (Saint-Louis, USA).

\section{Methods}

Cell line culture: Human GB U87MG/MGMT- cells were obtained from LGC (Molsheim, France). Human GB U87MG/MGMT+ cells were kindly provided by Professor Kaina Bernd (Mainz, Germany). These 
cells were cultured in Dubelcco's modified Eagle's medium (DMEM) supplemented with $10 \%$ of fetal bovine serum (FBS) (Lonza, Verviers, Belgium) and 1\% of antibiotics (Sigma Aldrich, Saint-Louis, USA) at $5 \% \mathrm{CO}_{2} / 37^{\circ} \mathrm{C}$.

Formulation of siRNA/chitosan-LNCs complexes: As previously described (27), LNCs with a diameter of $50 \mathrm{~nm}$ were prepared according to a phase-inversion process (28), and the chitosan grafting on their surface was obtained by a transacylation reaction. The final concentration of chitosan in nanoparticles formulation was $1.2 \mathrm{mg} /$ mL. Transacylated LNCs and siRNA were mixed in order to have a final concentration of chitosan-LNCs of $100 \mu \mathrm{g} / \mathrm{mL}$ and concentration of anti-EGFR and anti-galectin-1-siRNAs of $40 \mathrm{nM}$. The antiMGMT-siRNA concentration used was $5 \mathrm{nM}$. The siRNA sequences (Eurogentec, Angers, France) used are indicated in Table 1.

Characterization of siRNA/chitosan-LNCs complexes: The average hydrodynamic diameter, polydispersity index (PDI) and zeta potential of chitosan-LNCs and siRNA/chitosan-LNCs complexes were measured by DLS using NanoZS ${ }^{\circledR}$ (Malvern Instruments, Worcestershire, UK). Measurements were performed in RNAse free water in triplicate at $25^{\circ} \mathrm{C}$ with comparable conductivity values for zeta potential determination.

Stability of siRNA/chitosan-LNCs complexes: The stability of all siRNA/chitosan-LNCs complexes tested in this study was evaluated at 4 and $25^{\circ} \mathrm{C}$ in RNAse free water for $72 \mathrm{~h}$. For this purpose, measurements of hydrodynamic diameter, PDI and zeta potential were performed using a NanoZS ${ }^{\circledR}$.

siRNA transfection: U87MG/MGMT- or U87MG/MGMT+ were plated in 24-well plates at a density of $25 \times 10^{3}$ cells/well. After $48 \mathrm{~h}$, the culture medium was removed and cells were treated with siRNA/ chitosan LNC complexes. The final concentration of chitosan-LNCs was $100 \mu \mathrm{g} / \mathrm{mL}$. Anti-MGMT siRNA at the concentration of $5 \mathrm{nM}$ was tested on U87MG/MGMT + cells while anti-EGFR and anti-galectin-1 siRNAs (40 nM) was tested on U87MG/MGMT- cells.

Moreover, combinations of these siRNAs were also evaluated: (i) the effect of the combination of anti-EGFR and anti-galectin-1 siRNAs, on U87MG/MGMT- cells; and (ii) the combinations of anti-MGMT/ anti-EGFR siRNAs, anti-MGMT/anti-galectin-1 siRNAs or anti-MGMT/ anti-EGFR/anti-galectin-1siRNAs, on U87MGMGMT+ cells. The negative control tested was a scramble siRNA carried by chitosan-LNCs (Eurogentec, Angers, France).

Flow cytometry: Four days after the siRNA transfection, cells were harvested from the bottom of the plate by the Versene ${ }^{\circledR}$ (EDTA) $0.02 \%$

Table 1: Anti-MGMT, anti-EGFR and anti-galectin-1 siRNA sequences.

\begin{tabular}{ll}
\hline siRNA & Sequence \\
\hline Negative control & $\begin{array}{l}\text { sense: 5'-GGAAAUCCCCCAACAGUGAdTdT-3' } \\
\text { antisense: 5'-UCACUGUUGGGGGAUUUCCTdT-3' }\end{array}$ \\
Anti-MGMT & $\begin{array}{l}\text { sense: 5' GCUGGAGCUGUCUGGUUGUdTdT 3' } \\
\text { antisense: 3' dTdTCGACCUCGACAGACCAACA 5' }\end{array}$ \\
Anti-EGFR & $\begin{array}{l}\text { sense: 5' CACAGUGGAGCGAAUUCCUdTdT 3' } \\
\text { antisense: 3' dTdTGUGUCACCUCGCUUAAGGA 5' } \\
\text { Anti-galectin-1 }\end{array}$ \\
& $\begin{array}{l}\text { sense: 5' GCUGCCAGAUGGAUACGAAdTd 3' } \\
\text { antisense: 3' UUCGUAUCCAUCUGGCAGCdTdT 5' }\end{array}$ \\
\hline
\end{tabular}

(Lonza, Verviers, Belgium), re-suspended in PBS supplemented with $5 \% \mathrm{FBS}$ and $0.02 \% \mathrm{NaN}_{3}$ and incubated on ice for $1 \mathrm{~h}$ with mouse anti-EGFR and anti-MGMT (BD Biosciences, Le Pont de Claix, France), and mouse anti-galectin-1 (R\&D systems, Abingdon, UK) antibodies or isotype control antibodies.

For MGMT and galectin-1, cells were permeabilized with the BD cytofix/cytoperm ${ }^{\mathrm{TM}}$ fixation/permeabilization kit (BD Biosciences) before addition of primary antibodies. Following incubation, cells were washed and further stained with fluorescein isothiocyanate (FITC)-conjugated goat $\mathrm{F}\left(\mathrm{ab}^{\prime}\right)_{2}$ anti-mouse immunoglobulin (Dako, Trappes, France) or anti-goat immunoglobulin (R\&D systems) for 30 min on ice. Cells were then washed and fixed in $2 \%$ formaldehyde. The stained cells were analyzed in a FACScan flow cytometer with CellQuest Software (BD Biosciences, San Jose, CA, USA). Specific expression of the protein was defined as the ratio of the geometric mean of the respective antibody to the geometric mean of the isotype and further normalised to treatment versus control condition.

Survival assay: As aforementioned, U87MG/MGMT- or U87MG/ MGMT+ cells were plated for $48 \mathrm{~h}$ in 24-well plates and then treated for $72 \mathrm{~h}$ with siRNA/chitosan-LNCs complexes (siRNAs concentrations: $5 \mathrm{nM}$ for anti-MGMT and $40 \mathrm{nM}$ for anti-EGFR and anti-galectin-1 siRNAs).

At the end of the incubation period, the culture medium from each well was changed and cells were treated with or without TMZ. Two concentrations of TMZ were tested: 0.03 and $0.50 \mathrm{mg} / \mathrm{mL}$. After $24 \mathrm{~h}$, the culture medium was changed in each well and a volume of $40 \mu \mathrm{L}$ of the MTT reagent was added and incubated for $4 \mathrm{~h}$ in the dark at $37^{\circ} \mathrm{C}$. The supernatant was then aspirated and a volume of $400 \mu \mathrm{L}$ of acidic isopropanol was added to each well to dissolve the previously-obtained formazan crystals. The plate was left under mechanical stirring and the contents of each well was transferred to a 96-well plate to perform the reading Multiskan Ascent ${ }^{\circledR}$ (Labsystems, Haverhill, MA, USA) at $580 \mathrm{~nm}$.

Survival percentages were determined when compared to untreated cells which were taken as control with a $100 \%$ survival rate.

Statistical analysis: Results were expressed as mean values \pm standard error of the mean (SEM). Mann-Whitney U test was used for statistical comparison between controls and other groups. Differences were considered significant if $\mathrm{p}<0.05$.

\section{Results}

\section{Size and zeta potential of chitosan-LNCs and siRNA/chitosan-LNCs}

As previously described (27), an increase in the hydrodynamic diameter of the chitosan-LNCs compared to the LNCs was observed ( $71 \mathrm{~nm}$ and $52 \mathrm{~nm}$, respectively), confirming attachment of chitosan onto the surface of LNCs by the transacylation process (Table 2). The zeta potential of these chitosan-LNCs became positive ( -6 and $24 \mathrm{mV}$ for blank LNCs and chitosan-LNCs, respectively), allowing the fixation of siRNA on their surface by electrostatic 
Table 2: Size and zeta potential of chitosan-LNCs and siRNA/chitosan-LNCs complexes $(n=3)$.

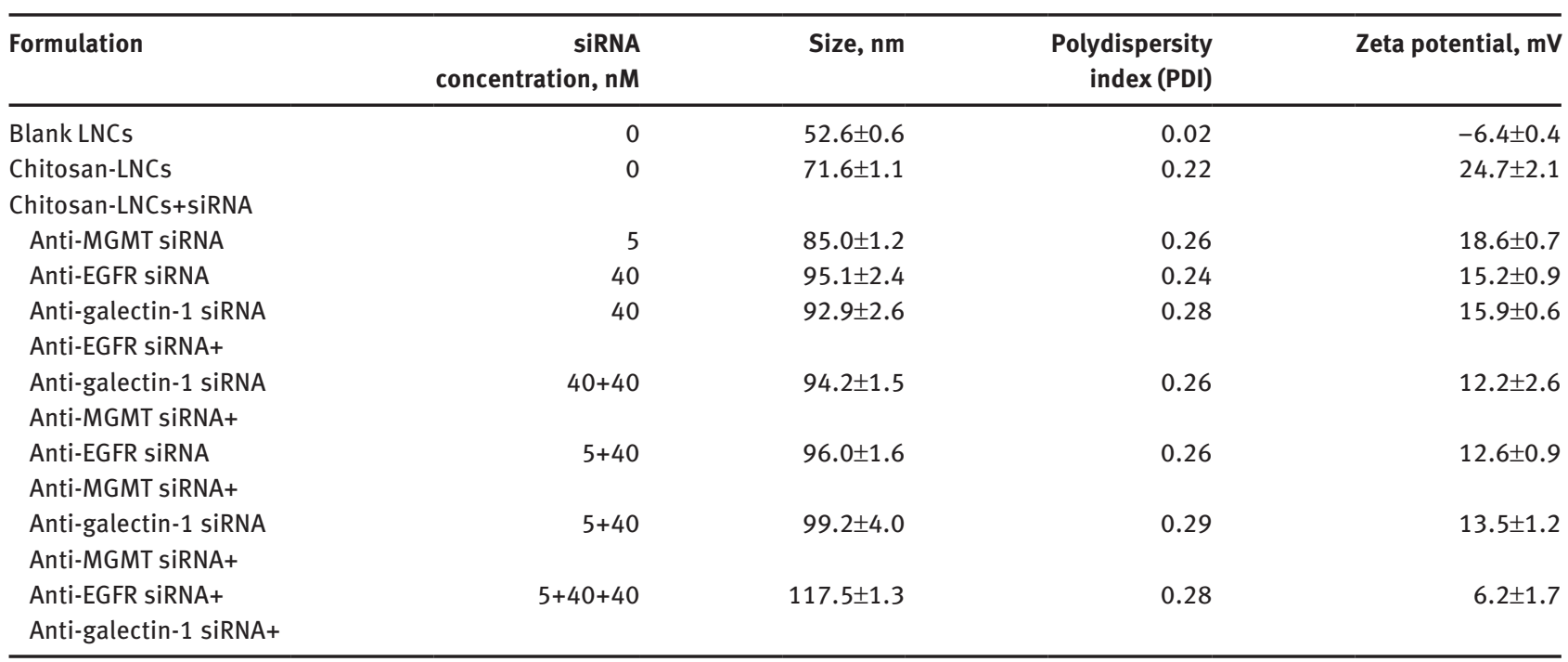

attraction (Table 2). Regarding the siRNA/chitosan-LNCs complex, an increase in the hydrodynamic diameter was observed compared to chitosan-LNCs ( $\pm 90 \mathrm{~nm}$ and $71 \mathrm{~nm}$, respectively). The zeta potentials of siRNA/chitosanLNCs decreased with the complexation of siRNA compared to chitosan LNCs ( $15 \mathrm{mV}$ and $24 \mathrm{mv}$, respectively) (Table 2) (27).

\section{Stability of siRNA/chitosan-LNCs complexes}

All complexes tested in this study were stable at $4^{\circ} \mathrm{C}$ and $25^{\circ} \mathrm{C}$ at least for $72 \mathrm{~h}$, in terms of hydrodynamic diameter, PDI and zeta potential. Example of the stability of antiEGFR/chitosan-LNCs (40 nM) is illustrated in Table 3. Additionally, the visual appearance of these formulations was identical at both temperatures. After this period, the

Table 3: Stability at $4^{\circ} \mathrm{C}$ and $25^{\circ} \mathrm{C}$ of anti-EGFR/chitosan-LNCs complexes $(40 \mathrm{nM})(\mathrm{n}=3)$.

\begin{tabular}{lrrrr}
\hline $\begin{array}{l}\text { Storage } \\
\text { temperature, }{ }^{\circ} \mathrm{C}\end{array}$ & Time, h & Size, $\mathbf{n m}$ & PDI & $\begin{array}{r}\text { Zeta } \\
\text { potential, mV }\end{array}$ \\
\hline 4 & 0 & $95.1 \pm 2.4$ & 0.24 & $15.2 \pm 0.9$ \\
& 24 & $96.4 \pm 1.0$ & 0.23 & $16.4 \pm 0.6$ \\
& 48 & $95.8 \pm 2.1$ & 0.25 & $15.9 \pm 0.7$ \\
72 & $97.2 \pm 1.0$ & 0.30 & $15.8 \pm 1.1$ \\
25 & 0 & $95.1 \pm 2.4$ & 0.24 & $15.2 \pm 0.9$ \\
& 24 & $95.7 \pm 2.8$ & 0.23 & $15.4 \pm 1.6$ \\
& 48 & $90.9 \pm 0.1$ & 0.26 & $16.0 \pm 0.9$ \\
& 72 & $95.9 \pm 2.4$ & 0.30 & $16.7 \pm 1.3$ \\
\hline
\end{tabular}

PDI of the formulations increased and exceeded 0.3 indicating the heterogeneity of particles sizes.

\section{Determination of protein expression by flow cytometry}

\section{Anti-MGMT siRNA}

The effect of anti-MGMT siRNA carried by chitosan-LNCs was assessed on the MGMT expression. The treatment of U87MG/MGMT+ cells for $96 \mathrm{~h}$, with anti-MGMT siRNA at the concentration of $5 \mathrm{nM}$ carried by chitosan-LNCs resulted in a significant reduction of the target protein, corresponding to expression of $68.3 \pm 2.9 \%$ compared to the siRNA negative control $(96.3 \pm 6.3 \%) \quad(p<0.05)$ (Figure 1).

\section{Anti-galectin-1 and EGFR siRNAs}

The effect of anti-galectin-1 and anti-EGFR (alone or in combination) siRNAs carried by chitosan-LNCs was assessed on their respective protein expression. The treatment of U87MG/MGMT- cells for $96 \mathrm{~h}$ with anti-galectin-1 siRNA induced a significant decrease in the expression of galectin-1 compared to siRNA negative control, corresponded to expression of $61.5 \pm 2.1 \%$ of the target protein when compared with $86.8 \pm 1.7 \%$ for the siRNA negative control $(\mathrm{p}<0.05)$ (Figure 2$)$. In a previous study, we demonstrated similar results for anti-EGFR siRNA (27). A similar expression of galectin-1 (58.8 $\pm 3.0 \%)$ was 


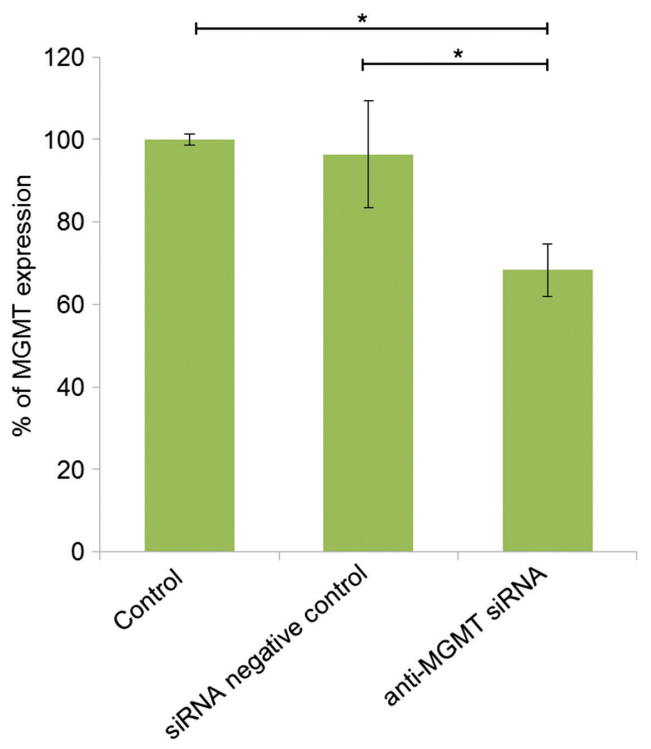

Figure 1: Effect of anti-MGMT siRNA ( $5 \mathrm{nM}$ ) carried by chitosan-LNCs on MGMT expression in U87MG/MGMT+ after siRNA treatment for 96 h. Data are shown as mean \pm SEM $(n=3)\left({ }^{\star} p<0.05\right)$.

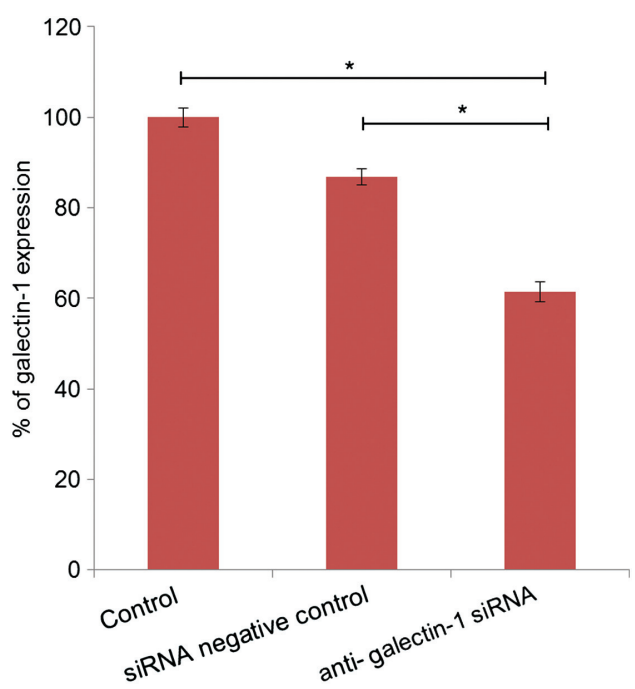

Figure 2: Effect of anti-galectin-1siRNA carried by chitosan-LNCS $(40 \mathrm{nM})$ on the galectin-1 expression in U87MG/MGMT- after treatment for $96 \mathrm{~h}$. Data are shown as mean \pm SEM $(n=3)\left({ }^{*} p<0.05\right)$.

obtained when the U87MG/MGMT- cells were treated with the combination of anti-EGFR and anti-galectin-1 siRNAs at a concentration of $40 \mathrm{nM}$ each one carried by the chitosan-LNCs when compared to the siRNA negative control $(86.8 \pm 1.7 \%)(p<0.05)$ (Figure 3$)$. In the same way, this combination induced a significant decrease of the EGFR expression, corresponding to expression of $54.1 \pm 1.5 \%$ compared to siRNA negative control $(79.6 \pm 3.2 \%)(\mathrm{p}<0.05)$ (Figure 3).

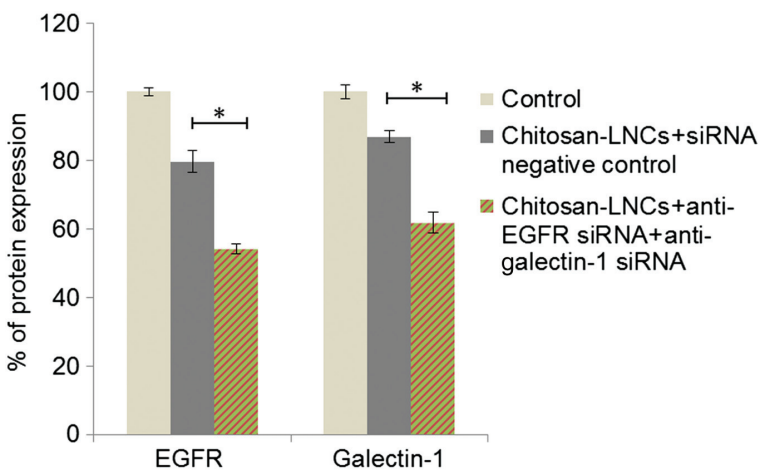

Figure 3: Effect of the combination of anti-EGFR ( $40 \mathrm{nM})$ and antigalectin-1 ( $40 \mathrm{nM}$ ) siRNAs carried by chitosan-LNCs on the EGFR and galectin-1 expression in U87MG/MGMT-cells. Data are shown as mean \pm SEM $(n=3)\left({ }^{*} p<0.05\right)$.

\section{Combination of anti-MGMT with galectin-1 and/or EGFR siRNAs}

The MGMT protein expression was significantly reduced compared to siRNA negative control after treatment with the combination of anti-MGMT/anti-EGFR, anti-MGMT/ anti-galectin-1 and anti-MGMT/anti-EGFR/anti-galectin-1 siRNAs for $96 \mathrm{~h}$. The percentages of MGMT expression were $67.8 \pm 4.6 \%, 64.2 \pm 2.3 \%$ and $80.3 \pm 1.7 \%$, respectively, when compared to $96.3 \pm 6.3 \%$ for siRNA negative control $(p<0.05)$ (Figure 4). The percentages of EGFR expression obtained after treatment of the same cells with the combination of anti-MGMT/anti-EGFR and anti-MGMT/anti-EGFR/antigalectin-1 siRNAs for $96 \mathrm{~h}$ were $62.6 \pm 2.7 \%$ and $74.6 \pm 1.4 \%$, respectively, when compared to $90.9 \pm 0.4 \%$ for siRNA negative control $(\mathrm{p}<0.05)$ (Figure 4). The expression of galectin-1 was also reduced compared to siRNA negative control after $96 \mathrm{~h}$ of incubation of these cells with the combinations of anti-MGMT/anti-galectin-1 and anti-MGMT/anti-EGFR/ anti-galectin-1 siRNAs. The percentages of galectin-1 expression were $69.1 \pm 6.5 \%$ and $77.2 \pm 5.1 \%$, respectively, when compared to $98.6 \pm 1.8 \%$ for siRNA negative control $(\mathrm{p}<0.05)$ (Figure 4). These results showed that the co-complexation of two or three siRNA did not reduce their ability to decrease the expression of their respective target protein.

\section{Evaluation of the sensitivity in U87MG cells to TMZ after siRNA treatment}

\section{Combination of anti-galectin- 1 and anti-EGFR siRNAs}

The treatment of U87MG/MGMT- cells with the antigalectin-1 siRNA carried by chitosan- LNCs at a 


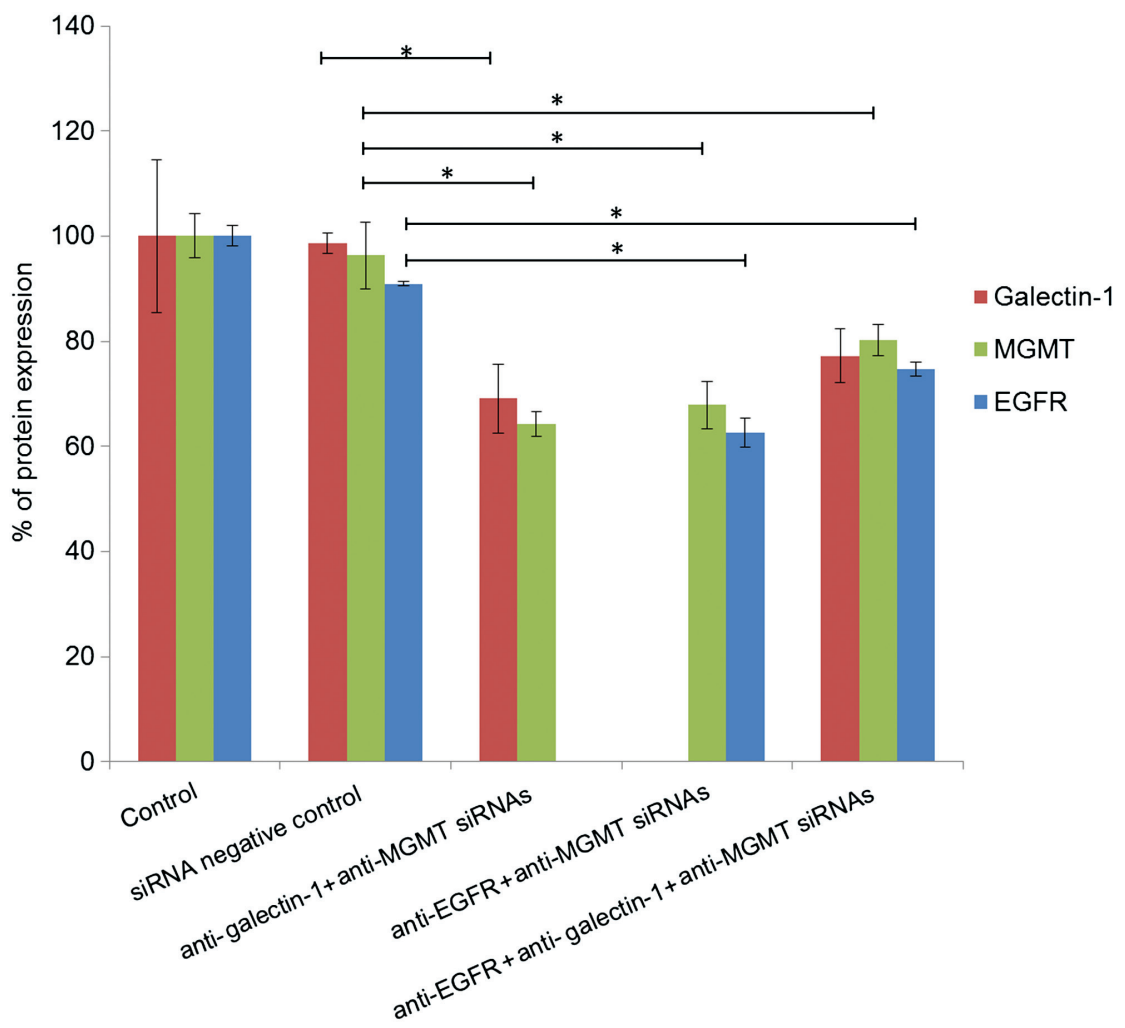

Figure 4: Effect on Galectin-1, MGMT and EGFR expression after treatment of U87MG/MGMT+ cells with the combination of siRNAs (antiMGMT/anti-EGFR, anti-MGMT/anti-galectin-1 and anti-MGMT/anti-EGFR/anti-Galectin-1) carried by the chitosan-LNCs. siRNAs concentrations were $40 \mathrm{nM}$ for anti-EGFR and anti-galectin-1 siRNAs and $5 \mathrm{nM}$ for the anti-MGMT siRNA. Data are shown as mean $\pm S E M(n=3)\left({ }^{\star} \mathrm{p}<0.05\right)$.

concentration of $40 \mathrm{nM}$ resulted in significant reduction of the percentages of living cells compared to siRNA negative control. Indeed, without TMZ, treatment with anti-galectin-1 siRNA allowed a percentage of living cells of $77.2 \pm 1.1 \%$ compared to $100 \pm 6.1 \%$ for siRNA negative control $(p<0.05)$. This effect was more pronounced for the combination of anti-galectin- 1 and antiEGFR siRNAs, reducing the percentage of living cells to $61.1 \pm 1.4 \%$ when compared with $77.2 \pm 1.1 \%(\mathrm{p}<0.05)$ and $100 \pm 6.1 \%(\mathrm{p}<0.05)$ for anti-galectin-1 siRNA alone and siRNA negative control (Figure 5). The effect of siRNA treatment was logically potentialized with the addition of TMZ. The percentage of living cells treated with antigalectin-1 siRNA and siRNA negative control was statistically different at $0.03(\mathrm{p}<0.05)$ and $0.5 \mathrm{mg} / \mathrm{mL}(\mathrm{p}<0.05)$ of TMZ (Figure 5). For example, at $0.5 \mathrm{mg} / \mathrm{mL}$ of TMZ, the anti-galectin-1 siRNA allowed a percentage of living cells of $40.6 \pm 3.8 \%$ when compared with $74.6 \pm 8.3 \%$ for siRNA negative control $(p<0.05)$ (Figure 5). The sensitivity of these cells to TMZ was significantly increased when antiEGFR and anti-galectin-1 siRNAs were combined. At 0.5 $\mathrm{mg} / \mathrm{mL}$ of TMZ, the percentage of living cells decreased from $40.7 \pm 3.7 \%$ to $17.8 \pm 1.6 \%$ for anti-galectin-1 alone and the combination of anti-galectin-1 and EGFR siRNAs, respectively $(\mathrm{p}<0.05)$. At $0.03 \mathrm{mg} / \mathrm{mL}$ of TMZ, the same conclusion can be observed (Figure 5).

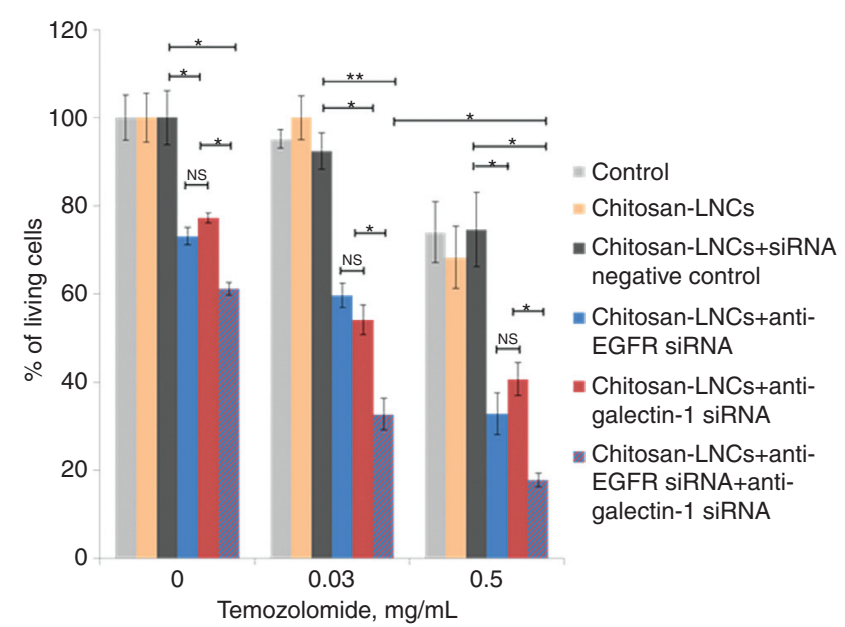

Figure 5: Evaluation of the sensitivity of U87MG/MGMT- cells to TMZ after SiRNA treatment. siRNAs concentrations were $40 \mathrm{nM}$ for anti-EGFR and anti-galectin-1 siRNAs. Data are shown as mean \pm SEM $(n=3)\left({ }^{*} p<0.05\right.$ and $\left.{ }^{* *} p<0.01\right)$. 


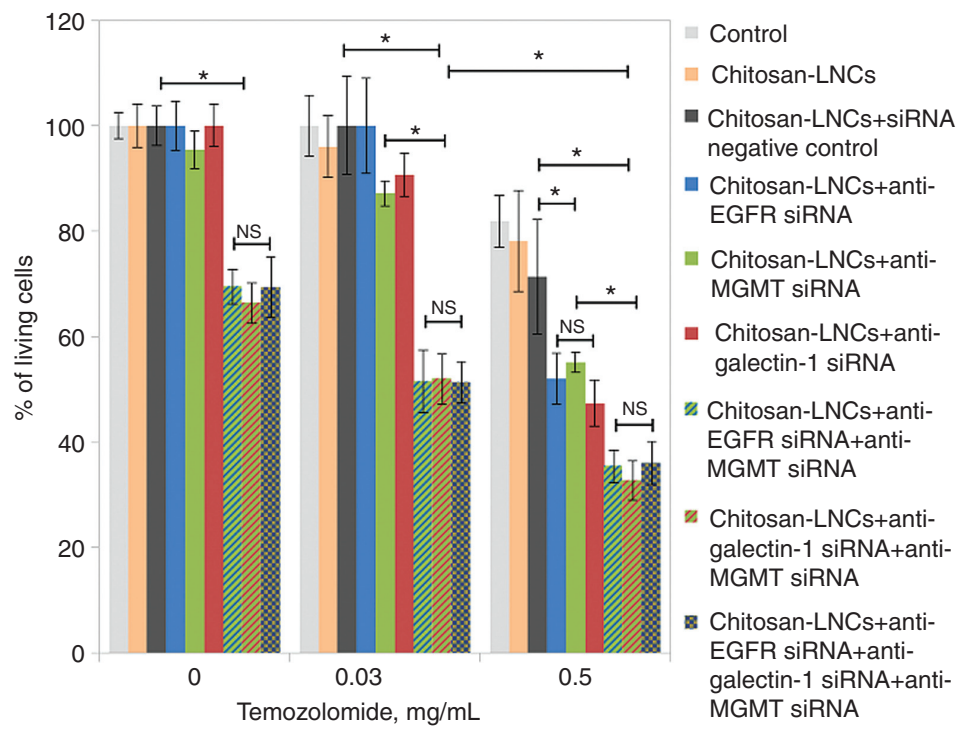

Figure 6: Evaluation of the sensitivity of U87MG/MGMT+ cells to TMZ after siRNA treatment. siRNAs concentrations were $40 \mathrm{nM}$ for antiEGFR and anti-galectin- 1 siRNAs and $5 \mathrm{nM}$ for the anti-MGMT siRNA. Data are shown as mean \pm SEM $(n=3) .\left({ }^{*} \mathrm{p}<0.05\right)$.

\section{Combination of anti-MGMT with anti-galectin-1 and/or anti-EGFR siRNAs}

The treatment of U87MG/MGMT+ cells with the antiMGMT siRNA alone (at the concentration of $5 \mathrm{nM}$ ) carried by chitosan-LNCs did not increase the sensitivity of these cells to TMZ compared to siRNA negative control. By contrast, when one or two siRNA (anti-galectin-1 or anti-EGFR) were combined to the anti-MGMT siRNA, the percentage of living cells (without TMZ treatment) decreased, suggesting the intrinsic cytotoxicity of these combinations $(\mathrm{p}<0.05)$. No difference was observed between the three combinations of siRNA (anti-MGMT/anti-EGFR; anti-MGMT/antigalectin-1 and anti-MGMT/anti-EGFR/anti-galectin-1). Logically, the cytotoxicity of theses combinations of siRNAs was enhanced in the presence of TMZ, showing the sensitization of cells to TMZ due to siRNA treatment. At $0.5 \mathrm{mg} / \mathrm{mL}$ of TMZ, the percentage of living cells decreased from $55.1 \pm 1.9 \%$ to $36.0 \pm 4.1 \%$ for anti-MGMT alone and the combination of anti-MGMT/anti-galectin-1/anti-EGFR siRNAs, respectively $(\mathrm{p}<0.05)$. At $0.03 \mathrm{mg} / \mathrm{mL}$ of TMZ, the same conclusion can be observed (Figure 6). Nevertheless, the combination of anti-MGMT with anti-galectin-1 or with anti-EGFR or with these two last ones did not present any statistical difference.

\section{Discussion}

In recent years, various mechanisms involved in the resistance to TMZ in GB patients have been elucidated such as, on one side, the overexpression of MGMT and on the other side, the overexpression of galectin-1 and $\operatorname{EGFR}(6,17,31)$. Finding ways to counter the expression and functionality of these proteins is a real challenge to sensitize GB cells to the first line treatment, TMZ. The development of siRNAbased nanotechnologies is very promising. For example, EGFRvIII has been targeted by Kim's team in GB cells by specific siRNA transported by cyclodextrin-modified dendritic polyamines (DexAMs) loaded with an anticancer drug, Erlotinib (32). The co-delivery of anti-EGFRvIII siRNA and Erlotinib in GB cells was found to significantly inhibit cell proliferation and induce apoptosis, as compared to the individual treatments. Kato et al., have used a mixture of anti-MGMT siRNAs carried by LipoTrust ${ }^{\mathrm{TM}}$ in GB cell lines, T98G and U251 which led to a significant increase in the sensitivity of these cell lines to TMZ compared with control (33). In another study, Le Mercier et al., have shown that reducing galectin-1 expression in glioma cells by siRNA increases the anti-tumor effects of various chemotherapeutic agents, in particular TMZ, both in vitro and in vivo (17). The main limitation of these studies consists is the use of vectors which are not easy to produce or which are not suitable for human injection. Furthermore, GBs are heterogeneous and highly proliferative tumors. Thus, targeting only one protein is not sufficient to increase significantly the sensitivity of the tumor to TMZ.

Many transport systems of siRNAs developed in recent years have high transfection efficiency and are produced using biocompatible and less toxic materials. The safety of vectors is an essential factor for clinical use which explains the low number of vectors used in clinical 
trials. Conventional systems such as PEI or lipofectamine ${ }^{\circledR}$ are widely used in vitro. However, their clinically use is not suitable despite their high efficiency of transfection of siRNA due to their toxicity profiles $(34,35)$.

In this work, we used chitosan-LNCs as vector for the delivery of siRNAs to target MGMT, EGFR and Galectin-1. These particles have the advantages to be produced through a simple process without solvent and simply purified by dialysis. This process has been previously adapted to produce large scale batches adapted to preclinical studies (36). Chitosan was used as polymer of transacylation, due to its interesting physicochemical properties, in particular, (i) its non-toxicity compared with other cationic polymers such as polyethylene imine (PEI) (37), and (ii) its high capacity for transfection of nucleic acids in particular siRNAs $(38,39)$. The concentration of $100 \mu \mathrm{g} / \mathrm{mL}$ of LNCs transacylated with $1.2 \mathrm{mg} / \mathrm{mL}$ of chitosan was selected based on previous cytotoxicity assay on U87MG cells showing that cytotoxicity of LNCs appeared from $150 \mu \mathrm{g} / \mathrm{mL}$ of LNCs (27). Previously, we showed that targeting EGFR by siRNA at the concentration of $40 \mathrm{nM}$ carried by chitosan-LNCs, reduced the expression of this protein and increased the sensitivity of U87MG/MGMTcells to TMZ (27). Based on these encouraging results, we hypothesized that the targeting of MGMT, EGFR and galectin-1 (alone or in combination) by specifics siRNAs carried by chitosan-lipid nanocapsules (chitosan-LNCs) could enhance the sensitivity of U87MG cells to TMZ. In this study, we demonstrated that the treatment of U87MG cells by anti-MGMT siRNA associated with chitosan-LNCs decreased the cellular expression of MGMT but did not increase the cytotoxic effect of TMZ. By contrast, when anti-MGMT siRNA was combined with anti-galectin-1 or anti-EGFR siRNAs, we observed a decrease of the cellular expression of MGMT (as well as those of galectin-1 or EGFR) and an increase of the cytotoxic effect of TMZ.

We also demonstrated that the treatment of U87MG cells by anti-galectin-1 or anti-EGFR siRNAs associated with chitosan-LNCs decreased the cellular expression of galectin-1 or EGFR and increased the cytotoxic effect of TMZ. This effect was enhanced when anti-galectin-1 and anti-EGFR siRNAs were combined. Indeed, using the same amount of nanoparticles to avoid any additional toxicity related to the vector, we showed that the combination of these two siRNAs significantly improved toxicity of TMZ on U87MG/MGMT- cells compared to the effect obtained with the siRNA used separately.

Two different concentrations of TMZ were tested: 0.03 and $0.5 \mathrm{mg} / \mathrm{mL}$. These concentrations were chosen taking into account both the sensitivity of U87MG cells and the plasma concentrations described in the literature.
The plasma concentration of TMZ was determined for patients with high grades gliomas. The pharmacokinetics of TMZ appeared linear, with the area under the curve (AUC) increasing proportionally to the dose after intravenous administration. For a dose of $250 \mathrm{mg} / \mathrm{m}^{2}$, the $\mathrm{C}_{\max }$ (maximum concentration) was $10 \mu \mathrm{g} / \mathrm{mL}$. Measured in the cerebrospinal fluid, concentration was about $29 \%$ of the plasma concentration (40). As expected, in combination with siRNA treatment, the higher the TMZ concentration, the higher cytotoxicity. Finally, we evaluated the effect of the combination of the three siRNAs. The combination of anti-MGMT with anti-galectin-1 and anti-EGFR siRNAs (with the same amount of nanoparticles) did not provide any additional effect than the combination of anti-MGMT with anti-galectin-1 or with anti-EGFR siRNAs, in terms of cellular expression of the target proteins and cellular sensitivity to TMZ. Additionnally, no difference was observed between the combination of anti-MGMT/anti-galectin-1 siRNAs and the combination of anti-MGMT/anti-EGFR siRNAs. These results highlighted the need to combine strategies of the two mains signaling pathways responsible of TMZ resistance.

siRNAs could be in competition with each other and also with endogenous miRNAs for the RISC complex incorporation, this may explain the effect obtained with three siRNAs (41). Additionally, we observed that the zeta potential of the complex formed by the association of the three siRNAs with chitosan-LNCs was divided by 2 compared to that of the combination of two siRNAs with chitosan-LNCs. Several studies indicated that the intensity of the positive charge of the nanocarriers increases cellular uptake of the complexes formed with siRNAs and the inhibition efficiency of the target proteins $(42,43)$. This could explain why chitosan-LNCs associated with three siRNAs failed to be more effective than other associations.

To combine three siRNAs, the increase of the amount of nanoparticles can be proposed but that may exceed the amount of vector-tolerated by cells. Another alternative consists in the increase of the particle size carrying siRNAs. Additional studies are conducted to validate this alternative. Nevertheless, the current formulation of the combined anti-MGMT/anti-galectin-1 or anti-MGMT/ anti-EGFR should be further evaluated in vivo. Our vector has been designed for intracerebral injection, a strategy which offers two advantages. First, it limits the interaction with plasma proteins observed with the intravenous route. That is why a noncovalent link between siRNA and LNCs seems adequate for transfection efficiency. Second, this approach solves the issue of crossing the bloodbrain barrier. In vivo, the formulation is better adapted to injection during tumor resection or can be injected in 
the tumor by the convection enhancement delivery (CED) using a stereotaxic procedure.

\section{Conclusion}

In this study, we showed in vitro that (i) anti-MGMT and (ii) anti-EGFR or anti-galectin-1 siRNAs decreased significantly the expression of their corresponding proteins. Additionally, the combination of anti-MGMT siRNA with either anti-EGFR or anti-galectin-1 siRNAs enhanced the sensitivity of U87MG cells to TMZ in comparison to their separately use. Interestingly, the association of the three siRNAs failed to be more effective than two siRNAs, showing that the properties of the vector have to be taken into account to optimize siRNA delivery and efficiency of their therapeutic activities.

These siRNA nanovectors due to their ease of preparation, the biocompatibility of their components and the possibility to encapsulate lipophilic drugs such as radiosensitizing agents represent a potential tool to improve the efficacy of the first line treatment of GB patients.

Acknowledgments: The authors are very grateful to the "Inter-Regional Committee, League against Cancer, Pays de la Loire region" for providing financial support for this work.

\section{References}

1. Stupp R, Hegi ME, Mason WP, van den Bent MJ, Taphoorn MJ, Janzer RC, et al. Effects of radiotherapy with concomitant and adjuvant temozolomide versus radiotherapy alone on survival in glioblastoma in a randomised phase III study: 5-year analysis of the EORTC-NCIC trial. Lancet Oncol 2009;10:459-66.

2. Stupp R, Mason WP, van den Bent MJ, Weller M, Fisher B, Taphoorn MJ, et al. Radiotherapy plus concomitant and adjuvant temozolomide for glioblastoma. N Engl J Med 2005;352:987-96.

3. Lefranc F, Sadeghi N, Camby I, Metens T, Dewitte 0, Kiss R. Present and potential future issues in glioblastoma treatment. Expert Rev Anticancer Ther 2006;6:719-32.

4. Pletsas D, Garelnabi EA, Li L, Phillips RM, Wheelhouse RT. Synthesis and quantitative structure-activity relationship of imidazotetrazine prodrugs with activity independent of 06-methylguanine-DNA-methyltransferase, DNA mismatch repair, and p53. J Med Chem 2013;56:7120-32.

5. Henry S. Friedman TK, Calvert H. Temozolomide and treatment of malignant glioma. Clin Cancer Res 2000;6:2585-97.

6. Zhang J, Stevens MF, Bradshaw TD. Temozolomide: mechanisms of action, repair and resistance. Curr Mol Pharmacol 2012;5:102-14.

7. Esteller M, Garcia-Foncillas J, Andion E, Goodman SN, Hidalgo OF, Vanaclocha V, et al. Inactivation of the DNA-repair gene MGMT and the clinical response of gliomas to alkylating agents. N Engl J Med 2000;343:1350-4.
8. Kaina B, Christmann M, Naumann S, Roos WP. MGMT: key node in the battle against genotoxicity, carcinogenicity and apoptosis induced by alkylating agents. DNA Repair (Amst) 2007;6:1079-99.

9. Yang RYC. Targeting the dimerization of epidermal growth factor receptors with small-molecule inhibitors. Chem Biol Drug Des 2010;76:1-9.

10. Ekstrand AJ, James CD, Cavenee WK, Seliger B, Pettersson RF, Collins VP. Genes for epidermal growth factor receptor, transforming growth factor alpha, and epidermal growth factor and their expression in human gliomas in vivo. Cancer Res 1991;51:2164-72.

11. Lo HW. EGFR-targeted therapy in malignant glioma: novel aspects and mechanisms of drug resistance. Curr Mol Pharmacol 2010;3:37-52.

12. Wikstrand CJ, Reist CJ, Archer GE, Zalutsky MR, Bigner DD. The class III variant of the epidermal growth factor receptor (EGFRvIII): characterization and utilization as an immunotherapeutic target. J Neurovirol 1998;4:148-58.

13. Guha A, Feldkamp MM, Lau N, Boss G, Pawson A. Proliferation of human malignant astrocytomas is dependent on Ras activation. Oncogene 1997;15:2755-65.

14. Narita Y, Nagane M, Mishima K, Huang HJ, Furnari FB, Cavenee WK. Mutant epidermal growth factor receptor signaling down-regulates p27 through activation of the phosphatidylinositol 3-kinase/Akt pathway in glioblastomas. Cancer Res 2002;62:6764-9.

15. Furuta S, Hidaka E, Ogata A, Yokota S, Kamata T. Ras is involved in the negative control of autophagy through the class I PI3kinase. Oncogene 2004;23:3898-904.

16. Liu FT, Rabinovich GA. Galectins as modulators of tumour progression. Nat Rev Cancer 2005;5:29-41.

17. Le Mercier M, Lefranc F, Mijatovic T, Debeir O, Haibe-Kains B, Bontempi G, et al. Evidence of galectin-1 involvement in glioma chemoresistance. Toxicol Appl Pharmacol 2008;229: 172-83.

18. Fire A, Xu S, Montgomery MK, Kostas SA, Driver SE, Mello CC. Potent and specific genetic interference by double-stranded RNA in Caenorhabditis elegans. Nature 1998;391:806-11.

19. McManus MT, Sharp PA. Gene silencing in mammals by small interfering RNAs. Nat Rev Genet 2002;3:737-47.

20. Aagaard L, Rossi JJ. RNAi therapeutics: principles, prospects and challenges. Adv Drug Deliv Rev 2007;59:75-86.

21. Kim DH, Rossi JJ. Strategies for silencing human disease using RNA interference. Nat Rev Genet 2007;8:173-84.

22. Reischl D, Zimmer A. Drug delivery of siRNA therapeutics: potentials and limits of nanosystems. Nanomedicine 2009; 5:8-20.

23. Volkov AA, Kruglova NS, Meschaninova MI, Venyaminova AG, Zenkova MA, Vlassov VV, et al. Selective protection of nucleasesensitive sites in SiRNA prolongs silencing effect. Oligonucleotides 2009;19:191-202.

24. Fehring V, Schaeper U, Ahrens K, Santel A, Keil O, Eisermann M, et al. Delivery of therapeutic siRNA to the lung endothelium via novel lipoplex formulation DACC. Mol Ther 2014;22:811-20.

25. Katas H, Abdul Ghafoor Raja M, Ee LC. Comparative characterization and cytotoxicity study of TAT-peptide as potential vectors for siRNA and Dicer-substrate siRNA. Drug Dev Ind Pharm 2014;40:1443-50. 
26. Pantazis P, Dimas K, Wyche JH, Anant S, Houchen CW, Panyam J, et al. Preparation of siRNA-encapsulated PLGA nanoparticles for sustained release of siRNA and evaluation of encapsulation efficiency. Methods Mol Biol 2012;906:311-9.

27. Messaoudi K, Saulnier P, Boesen K, Benoit JP, Lagarce F. Anti-epidermal growth factor receptor siRNA carried by chitosan-transacylated lipid nanocapsules increases sensitivity of glioblastoma cells to temozolomide. Int J Nanomedicine 2014;9:1479-90.

28. Heurtault B, Saulnier P, Pech B, Proust JE, Benoit JP. A novel phase inversion-based process for the preparation of lipid nanocarriers. Pharm Res 2002;19:875-80.

29. Hureaux J, Lagarce F, Gagnadoux F, Vecellio L, Clavreul A, Roger E, et al. Lipid nanocapsules: ready-to-use nanovectors for the aerosol delivery of paclitaxel. Eur J Pharm Biopharm 2009;73:239-46.

30. Malmo J, Sorgard H, Varum KM, Strand SP. siRNA delivery with chitosan nanoparticles: Molecular properties favoring efficient gene silencing. J Control Release 2012;158:261-8.

31. Shinojima N, Tada K, Shiraishi S, Kamiryo T, Kochi M, Nakamura $\mathrm{H}$, et al. Prognostic value of epidermal growth factor receptor in patients with glioblastoma multiforme. Cancer Res 2003;63:6962-70.

32. Kim C, Shah BP, Subramaniam P, Lee KB. Synergistic induction of apoptosis in brain cancer cells by targeted codelivery of siRNA and anticancer drugs. Mol Pharm 2011;8:1955-61.

33. Kato T, Natsume A, Toda H, Iwamizu H, Sugita T, Hachisu R, et al. Efficient delivery of liposome-mediated MGMT-siRNA reinforces the cytotoxity of temozolomide in GBM-initiating cells. Gene Ther 2010;17:1363-71.

34. Lungwitz U, Breunig M, Blunk T, Gopferich A. Polyethyleniminebased non-viral gene delivery systems. Eur J Pharm Biopharm 2005;60:247-66.

35. Xue HY, Liu S, Wong HL. Nanotoxicity: a key obstacle to clinical translation of siRNA-based nanomedicine. Nanomedicine (Lond) 2014;9:295-312.

36. Thomas 0 , Lagarce F. Lipid nanocapsules: a nanocarrier suitable for scale-up process. J Drug Del Sci Tech 2013;23:555-9.

37. Fischer D, Bieber T, Li Y, Elsasser HP, Kissel T. A novel nonviral vector for DNA delivery based on low molecular weight, branched polyethylenimine: effect of molecular weight on transfection efficiency and cytotoxicity. Pharm Res 1999;16:1273-9.

38. Howard KA, Rahbek UL, Liu X, Damgaard CK, Glud SZ, Andersen MO, et al. RNA interference in vitro and in vivo using a novel chitosan/siRNA nanoparticle system. Mol Ther 2006;14:476-84.

39. Katas H, Alpar HO. Development and characterisation of chitosan nanoparticles for siRNA delivery. J Control Release 2006;115:216-25

40. Gander M, Leyvraz S, Decosterd L, Bonfanti M, Marzolini C, Shen $\mathrm{F}$, et al. Sequential administration of temozolomide and fotemustine: depletion of 06-alkyl guanine-DNA transferase in blood lymphocytes and in tumours. Ann Oncol 1999;10:831-8.

41. Castanotto D, Sakurai K, Lingeman R, Li H, Shively L, Aagaard L, et al. Combinatorial delivery of small interfering RNAs reduces
RNAi efficacy by selective incorporation into RISC. Nucleic Acids Res 2007;35:5154-64.

42. Hattori Y, Yoshizawa T, Koga K, Maitani Y. NaCl induced high cationic hydroxyethylated cholesterol-based nanoparticlemediated synthetic small interfering RNA transfer into prostate carcinoma PC-3 cells. Biol Pharm Bull 2008;31:2294-301.

43. Huang HY, Kuo WT, Chou MJ, Huang YY. Co-delivery of antivascular endothelial growth factor siRNA and doxorubicin by multifunctional polymeric micelle for tumor growth suppression. J Biomed Mater Res A 2011;97:330-8.

\section{Bionotes}

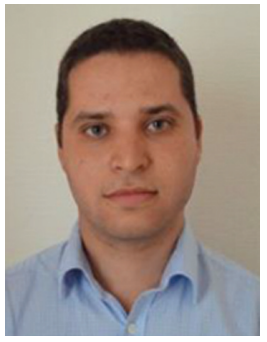

Khaled Messaoudi

LUNAM Université, Angers, France; Inserm U1066, Micro et Nanomédecines Biomimétiques, IBS, Angers Cedex 9, France

Khaled Messaoudi obtained his PhD thesis from 2011 to 2014 at the University of Angers in the U1066 Inserm Unit of Professor JeanPierre Benoit. He has worked on the design of lipid-nanocapsule surface modified by grafting of chitosan in order to carry siRNA. This strategy was tested on human glioblastoma cells and a brain tumor model implanted in nude mice. His work has helped to produce scientific publications published in international journals. Currently he is Assistant of Immunology at University Hospital of Clermont-Ferrand.

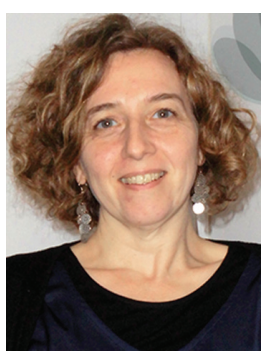

Anne Clavreul

LUNAM Université, Angers, France; Inserm U1066, Micro et Nanomédecines Biomimétiques, IBS, Angers Cedex 9, France

Anne Clavreul is a hospital engineer at the $\mathrm{CHU}$ of Angers. After her $\mathrm{PhD}$ in fundamental immunology, she joined the team of Professor Philippe Menei of the Neurosurgery Department. Clavreul's work focuses on the understanding of the recurrence mechanisms of glioblastoma. In particular, her main interest is the characteristics of the peritumoral zone of glioblastoma where $90 \%$ of recurrences occur. Together with her collaborators she investigates the development of targeted therapies against glioblastoma such as the use of mesenchymal stem cells which have endogenous tumor-homing activity for the targeted delivery of lipid nanocapsules loaded with therapeutic agents to the tumor. 


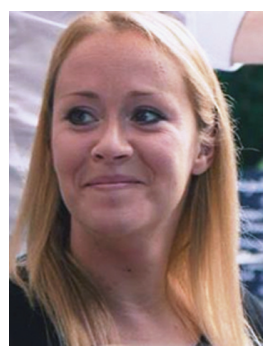

Fabienne Danhier

Louvain Drug Research Institute, Université catholique de Louvain, Advanced Drug Delivery and Biomaterials, Avenue Mounier 73 bte B1 73.12, B-1200 Brussels, Belgium

Fabienne Danhier received her PhD in 2010 from the Université catholique de Louvain in Biomedical and Pharmaceutical Sciences. She is currently a post-doctoral researcher. Her research interest is in the field of designing nanomedicines and hydrogels for anti-cancer drug delivery. Danhier also focuses her attention on the understanding of the influence of nanomedicines on the tumor microenvironment.

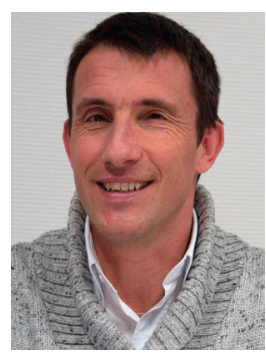

\section{Patrick Saulnier}

LUNAM Université, Angers, France; Inserm U1066, Micro et Nanomédecines Biomimétiques, IBS, Angers Cedex 9, France

Patrick Saulnier, trained in Physical-Chemistry in the University of Pau, France, and teaches Biophysics and Biostatistics at the School of Pharmacy, Angers University. He acquired a solid foundation in the domain of bicontinuous systems (microemulsions, liquid crystals, micellar assemblies) and more particularly in the methods used to synthesize and to characterize them. His research, at the frontiers of physical chemistry and the pharmaceutical technology, concerns the development of colloidal systems formulated at the nanometric scale and used as drug delivery systems. More particularly Saulnier has initiated the formulation of lipidic core and aqueous core nanocapsules from which the size can be chosen in a 20-200 nm range. On these objects, he has performed different physical and chemical modifications allowing a better encapsulation of a large drug properties spectrum. He has worked also on a better control of the interfacial properties of the final loaded nano objects. Also he has developed different physical models in order to characterize the comportment of the nanoparticles in a given biologic environment. His work has been valorized by 85 international papers and six patents. The key words that match Saulnier's competences are Biostatistics, Nanoparticles, Drug Targeting, Physical-Chemistry of Interfaces and Colloidal Systems

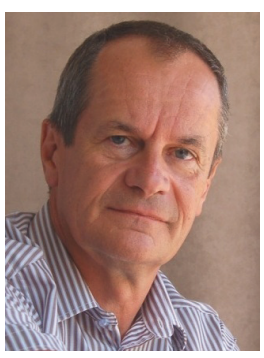

\section{Jean-Pierre Benoit}

LUNAM Université, Angers, France; Inserm U1066, Micro et Nanomédecines Biomimétiques, IBS, Angers Cedex 9, France; and Service Pharmacie, $\mathrm{CHU}$ Angers, France

Professor Jean-Pierre Benoit, trained in Pharmacy, and teaches Pharmaceutical Technology at the Faculty of Pharmacy, Angers University. He acquired a solid foundation in the domain of microand nanoencapsulation. He has developed a highly competitive research group at an international level. Jean-Pierre Benoit is currently the director of a 70-members strong research team, which is recognized and financed by INSERM. His research activity has resulted in the publication of over 260 original refereed scientific articles and reviews, and 25 patents. In 2010 Benoit received the PSWC Research Achievement Award in New Orleans from the FIP, and in 2011 the Prize of Notoriety from the French National Academy of Pharmacy.

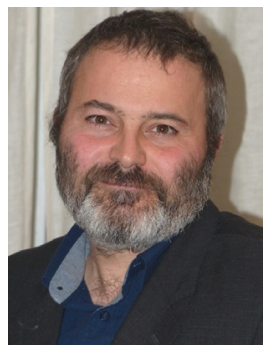

\section{Frederic Lagarce}

LUNAM Université, Angers, France; Inserm U1066, Micro et Nanomédecines Biomimétiques, IBS, Angers Cedex 9 , France; and Service Pharmacie, CHU Angers, France frederic.lagarce@univ-angers.fr

Frederic Lagarce received his PhD in 2004, and is Professor of Pharmaceutical Technology and Biopharmaceutics since 2012 at the University of Angers in France. Being also a Hospital Pharmacist, his research is translational (from bench to bedside) and mainly focused on cancer therapy, especially on bioavailability enhancement by playing on the interactions between drug products (mainly nanosystems) and living tissues. This field involves biological barrier crossing studies but also stability assessment of the active moieties and overcoming the acquired resistances to drugs. Finding new answers to medical needs using innovative drug formulations is what drives him every day to work. 